CARADDE: Jurnal Pengabdian Kepada Masyarakat
$\begin{gathered}\text { https://journal.ilininstitute.com/index.php/caradde } \\ \text { Volume 2 I Nomor 1 I Agustus I2019 } \\ \text { e-ISSN: 2621-7910 dan p-ISSN: 2621-7961 }\end{gathered}$

\title{
Workshop Penataan Indikator Kinerja Program dan Kegiatan pada Dinas Pengelolaan Sumber Daya Air
}

\author{
Jovan Febriantoko ${ }^{1}$ Febrianty $^{2}$, Hendra Hadiwijaya ${ }^{3}$
}

Keywords :

Indikator Kinerja;

Logic Model;

Performance Measurement;

Pengabdian Masyarakat;

\section{Corespondensi Author}

Akuntansi, Politeknik Palcomtech,

Palembang

Email:

jovan_febriantoko@palcomtech.ac.id

\section{History Artikel}

Received: Juni-2019;

Reviewed: Juni -2019

Accepted: Juli-2019

Published: Agustus-2019

\begin{abstract}
Abstrak. Tujuan dari kegiatan sesuai dengan judul Workshop Penataan Indikator Kinerja Program dan Kegiatan pada Dinas PSDA Provinsi Sumsel. Dinas PSDA Provinsi Sumsel telah mengikuti berbagai pelatihan namun pemahamannya masih Kegiatan Pengabdian Kepada Masyarakat ini dilaksanakan di Dinas PSDA Provinsi Sumsel. Manfaat bagi peserta bisa memperoleh tambahan pengetahuan tentang pendekatan logic model yang dapat digunakan sebagai alat pengukuran kinerja dan evaluasi program di Dinas PSDA Provinsi Sumsel. Keberhasilan dari pelaksanaan program pengabdian masyarakat ini dilihat dari dua sebagai indikator adalah respon positif dari peserta, peserta pelatihan sangat antusias dalam mengikuti pelatihan ini. Terlihat dari keaktifan mereka dalam tanya jawab, materi yang disampaikan bermanfaat bagi Dinas PSDA Provinsi Sumsel dan menambah wawasan bagi penyusun indikator kinerja, permintaan peserta workhop untuk melakukan bimbingan teknis berkelanjutan dan terstruktur, terpotong-potong dan Teknologi Informasi yang ada saat ini belum mendukung. Metode pelaksanaan kegiatan pengabdian masyarakat dimulai dari sosialisasi. Pemaparan logic model, diskusi dan tanya jawab, serta menggali persoalan mitra lebih dalam dan kemitraan kegiatan terkait dengan indikator kinerja program dan kegiatan.
\end{abstract}

\section{PENDAHULUAN}

Di Indonesia akuntabilitas kinerja publik mulai ditekankan sejak diterbitkannya Instruksi Presiden (Inpres) Nomor 9 Tahun 1999 tentang Akuntabiltas Kinerja Instansi Pemerintah (AKIP) yang menyebutkan bahwa diperlukannya sistem pelaporan akuntabilitas kinerja instansi pemerintah untuk mengetahui kemampuannya dalam pencapaian visi, misi dan tujuan organisasi. Disebutkan pula bahwa instansi pemerintah memiliki kewajiban untuk merancang program dan kegiatannya yang berorientasi pada hasil yang ingin dicapai.

Dalam praktiknya pengukuran kinerja instansi pemerintah di Indonesia ternyata masih didominasi oleh faktor regulasi, di mana penyusunan dan pelaporan indikator kinerja dibuat karena adanya peraturan yang mewajibkan instansi pemerintah untuk membuatnya, bukan karena didorong oleh keasadaran akan pentingnya laporan tersebut bagi instansi yang bersangkutan(Febriantoko and Febrianty 2017). 
Caradde: Jurnal Pengabdian Kepada Masyarakat

Vol 2 No 1, Agustus 2019

\begin{abstract}
Dinas PSDA Provinsi Sumsel merupakan salah satu Satuan Kerja Perangkat Daerah (SKPD) yang menjalankan fungsi penting yang didanai oleh APBD. Sebagaimana halnya instansi pemerintah lainnya, SKPD juga diwajibkan membuat RKA-SKPD dan LAKIP sebagai laporan pencapaian kinerjanya. SKPD yang merupakan pelaksana fungsi eksekutif harus berkoordinasi dengan melaksanakan pengukuran kinerja dan menyusun laporan pencapaian indikator kinerja agar penyelenggaraan pemerintaahan berjalan dengan baik(Mayasari and Febriantoko 2018). Kesuksesan SKPD dalam pencapaian kinerja menjadi salah satu kunci keberhasilan pembangunan daerah. Namun pemahaman akan pelaksanaan pengukuran kinerja di lingkungan SKPD nampaknya masih terpotong-potong, belum jelas pencapaiannya, dan dilaksanakan hanya karena faktor kewajiban bukan kesadaran(Febriantoko and Mayasari 2018).
\end{abstract}

Berdasarkan latar belakang di atas maka diajukan judul pengabdian masyarakat dengan judul "Penataan Indikator Kinerja Program dan Kegiatan pada Dinas Pengelolaan Sumber Daya Air Provinsi Sumsel Berorientasi Output dan Outcome." Program Pengabdian Masyarakat ini dilaksanakan di Dinas PSDA Provinsi Sumselpada tanggal 2 Juli 2018 dengan peserta dari staf Dinas PSDA Provinsi Sumsel pada sebagian besar dari divisi perencanaan, pelaporan dan keuangan. Berdasarkan hasil diskusi bersama staf Dinas PSDA Provinsi Sumsel diketahui bahwa pihak Dinas PSDA Provinsi Sumsel telah mengikuti berbagai pelatihan namun pemahamannya masih terpotong-potong dan Teknologi Informasi yang ada saat ini belum mendukung.Berdasarkan hasil observasi di lapangan tidak terdapat teknologi informasi yang membantu tercapainya indikator kinerja berorientasi terhadap dampak. Selain itu berdasarkan penelitian yang dilakukan oleh (Mayasari 2016) menunjukkan sebagian besar indikator kinerja yang digunakan masih berupa upaya yang dilakukan belum menunjukkan dampak yang telah dicapai oleh Dinas PSDA Provinsi Sumsel

Berdasarkan latar belakang yang menjadi tujuan dari kegiatan Workshop Penataan Indikator Kinerja Program dan
Kegiatan pada Dinas PSDA Provinsi Sumsel adalah untuk memberikan pengenalan pendekatan dalam proses evaluasi indikator kinerja dalam dokumen perencanaan Dinas PSDA Provinsi Sumsel dan memberikan kemungkinan penggunaan teknologi informasi sebagai alat untuk membantu memperbaiki indikator kinerja.

Manfaat yang diperoleh dari pelaksanaan program pengabdian ini adalah bagi peserta bisa memperoleh tambahan pengetahuan tentang pendekatan logic model yang dapat digunakan sebagai alat pengukuran kinerja dan evaluasi program di Dinas PSDA Provinsi Sumsel dan mendapatkan gambaran umum mengenai teknologi informasi yang dapat di implementasikan di Dinas PSDA Provinsi Sumatera Selatan..

\section{METODE}

Metode pelaksanaan pengabdian ini adalah dengan cara langsung melakukan pengenalan logic model sebagai alat evaluasi dengan sosialisasi yaitu memberikan penjelasan materi tentang manajemen sektor publik, paparan pengenalan logic model secara singkat, tanya jawab yaitu peserta diberikan kesempatan untuk bertanya tentang penyusunan indikator kinerja dalam RKA SKPD, menggali kebutuhan mitra pengabdian dalam penyusunan indikator kinerja dalam RKA SKPD, kemitraan kegiatan yang berkelanjutan tentang indikator kinerja program dan kegiatan.

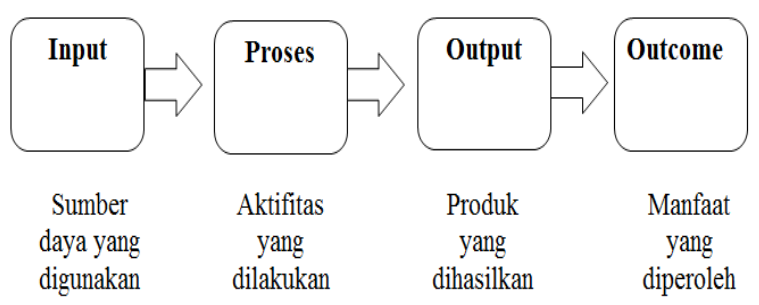

Sumber: (Kellogg, 2009)

Gambar 1. Logic Model Sederhana

Logic Model adalah gambaran visual logis dari suatu program yang menunjukkan rangkaian/hubungan antara input, proses sampai dengan output dan outcome yang dihasilkan sebagai respon terhadap suatu situasi yang dihadapi organisas(Febriantoko and Rotama 2018)(Sherman 2016). 
Febriantoko, Febrianty, Hadiwijaya. Workshop Penataan Indikator

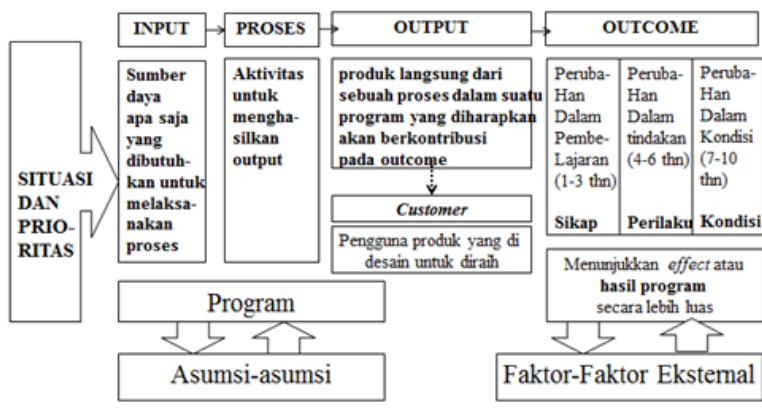

Gambar 2. Gambaran IPTEK

\section{HASIL DAN PEMBAHASAN}

Rencana Kerja dan Anggaran (RKA) merupakan dokumen perencanaan dan penganggaran yang berisi rencana pendapatan, rencana belanja program dan kegiatan SKPD serta rencana pembiayaan sebagai dasar penyusunan $\mathrm{APBD}($ Febrianty and Febriantoko 2017). Dalam rangka mewujudkan reformasi sistem perencanaan dan penganggaran, diperlukan menetapkan 3 pendekatan penting yaitu anggaran terpadu, anggaran berbasis kinerja, dan kerangka pengeluaran jangka menengah. Penyusunan Rencana Kerja Anggaran terpadu dilakukan dengan cara mengintegrasikan seluruh proses perencanaan dan penganggaran di Pemerintah Daerah(Damat 2011).

Prinsip dasar penyusunan RKA adalah dengan Prinsip Kerangka Jangka Menengah, pendekatan mendasarkan kebijakan dengan perspektif lebih dari satu tahun anggaran dengan mempertimbangkan implikasi biaya akibat keputusan tahun berikutnya (perkiraan maju anggaran), Prinsip Perkiraan Maju (forward estimate) yaitu perhitungan anggaran untuk tahun berikutnya dari tahun yang direncanakan guna memastikan kesinambungan program kegiatan yang telah disetujui \& menjadi dasar penyusunan anggaran tahun berikutnya, Prinsip anggaran berbasis prestasi kerja (kinerja), pendekatan penganggaran yang mengutamakan keluaran/hasil dari kegiatan yang akan atau telah dicapai sehubungan dengan penggunaan anggaran dengan kuantitas dan kualitas yg terukur, Prinsip penganggaran terpadu (unified budgeting), penyusunan rencana keuangan tahunan yang dilakukan secara terintegrasi untuk seluruh jenis belanja guna melaksanakan kegiatan pemerintahan yang didasarkan pada prinsip pencapaian efisiensi alokasi dana
Indikator Kinerja Program (outcome/hasil) adalah sesuatu yang mencerminkan berfungsinya keluaran kegiatan pada jangka menengah (efek langsung)(Mayasari and Junaidi 2018)(Febriantoko 2016). Pengukuran indikator hasil seringkali rancu dengan indikator keluaran. Indikator hasil lebih utama daripada sekedar keluaran. Walaupun output telah berhasil dicapai dengan baik, belum tentu outcome kegiatan tersebut telah tercapai. Outcome menggambarkan tingkat pencapaian atas hasil lebih tinggi yang mungkin mencakup kepentingan banyak pihak(Kellogg 2009). Dengan indikator outcome, organisasi akan mengetahui apakah hasil yang telah diperoleh dalam bentuk output memang dapat dipergunakan sebagaimana mestinya dan memberikan kegunaan yang besar bagi masyarakat banyak.

Kegiatan Pengabdian Kepada Masyarakat ini dilaksanakan di Dinas PSDA Provinsi Sumsel. Keberhasilan dari pelaksanaan program pengabdian masyarakat ini dilihat dari dua sebagai indikator yaitu respon positif dari peserta, peserta pelatihan sangat antusias dalam mengikuti pelatihan ini. Terlihat dari keaktifan mereka dalam tanya jawab, materi yang disampaikan bermanfaat bagi Dinas PSDA Provinsi Sumsel dan menambah wawasan bagi penyusun indikator kinerja, permintaan peserta workhop untuk melakukan bimbingan teknis berkelanjutan dan terstruktur.

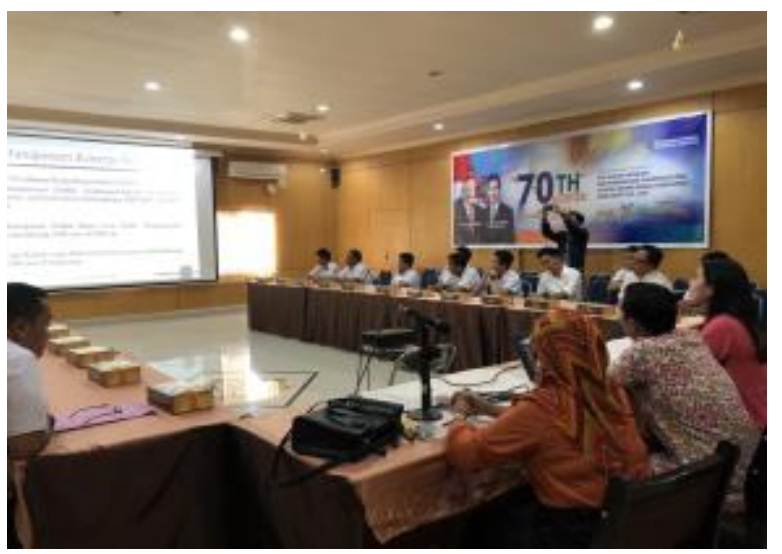

Gambar 3. Suasana Workshop di Dinas PSDA Provinsi Sumsel 
Caradde: Jurnal Pengabdian Kepada Masyarakat

Vol 2 No 1, Agustus 2019

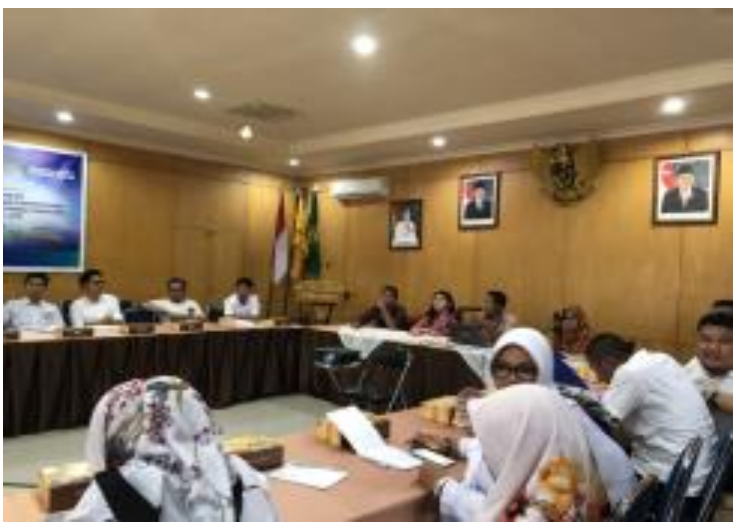

Gambar 4. Sesi Tanya Jawab Terkait Penyusunan Indikator kinerja dalam RKA

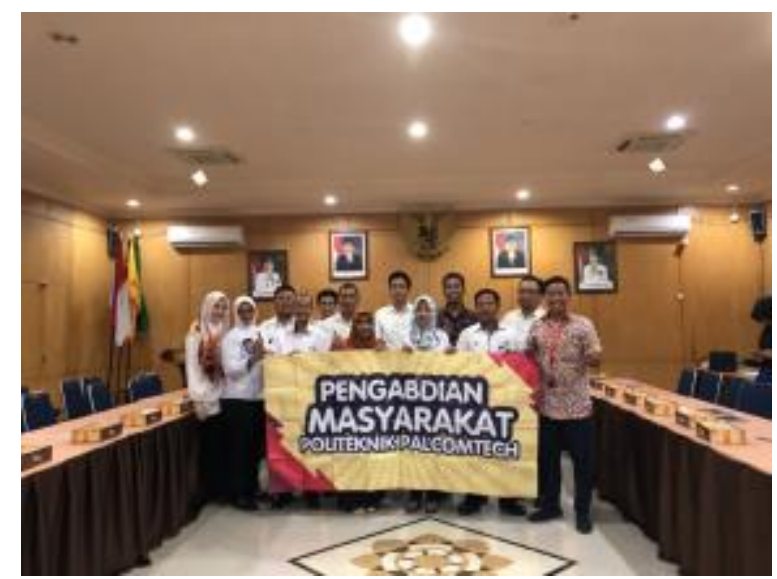

Gambar 5. Foto bersama Aparatur Dinas PSDA Propinsi Sumsel

\section{SIMPULAN DAN SARAN}

Kegiatan dari Pengabdian Masyarakat ini telah terlaksana dengan baik, sebagian besar peserta dapat mengenal tentang logic model sebagai alat pengukuran kinerja dan evaluasi program. Hasil evaluasi pelaksanaan kegiatan tersebut terdapat beberapa hal yang harus ditingkatkan untuk lebih memperbaiki hasil diantaranya adalah durasi pelatihan yang dirasa peserta masih kurang dan belum adanya teknologi informasi yang mampu mempermudah dalam pengukuran kinerja. Beberapa hal yang dapat disarankan untuk kegiatan sejenis kedepannya adalah durasi pelatihan dapat ditambah agar materi yang disampaikan dapat terserap dengan baik dan memberikan software agar mempermudah proses pengukuran kinerja.

\section{UCAPAN TERIMAKASIH}

Ucapan terimakasih yang sebesarbesarnya kepada pihak Dinas Pengelolaan Sumber Daya Air (PSDA) Provinsi Sumsel dan LPPM Politeknik Palcomtech, yang telah memberikan kemudahan dan turut memfasilitasi kelacaran pelaksanaan Kegiatan Pengabdian Masyarakat ini.

\section{DAFTAR RUJUKAN}

Damat, Maulana. 2011. "Evaluasi Terhadap Perencanaan Dan Penyusunan Anggaran Berbasis Kinerja Di Rumah Sakit Umum Daerah Namlea Kabupaten Buru-Maluku." Universitas Gadjah Mada.

Febriantoko, Jovan. 2016. "Evaluasi Penyusunan Rencana Kerja Anggaran Studi Pada Dinas Pekerjaan Umum Kabupaten Wonogiri." Universitas Gadjah Mada.

Febriantoko, Jovan and Febrianty. 2017. "Proses Penyusunan Dokumen Perencanaan Dan Laporan Pertanggung Jawaban Pemerintah Daerah Di Indonesia: Pendekatan Kualitatif." Media Trend 12((2)):143-55.

Febriantoko, Jovan and Riana Mayasari. 2018. "17 Years of Establishment of Pagaralam as a Tourism City: How Is the Tourism Sector' s Ability to Increase Original Local Government Revenue?" International Journal of Scientific Engineering and Science 2(9):61-64.

Febriantoko, Jovan and Hendra Rotama. 2018. "Evaluasi Potensi Penerimaan Pendapatan Asli Daerah Bidang Pariwisata Di Indonesia." Ekuivalensi 4(2):1-15.

Febrianty and Jovan Febriantoko. 2017. "Pengaruh Implementasi Sistem Informasi Akuntansi Manajemen (Siam), Desentralisasi, Dan Kejelasan Sasaran Anggaran Terhadap Kinerja Penyusunan Anggaran Kabupaten Empat Lawang." Jurnal Ilmiah Ekonomi Dan Bisnis 14(2):181-94. 
Febriantoko, Febrianty, Hadiwijaya. Workshop Penataan Indikator

Kellogg, W. .. 2009. Developing a Theory of Change. A Guide to Developing a Theory of Change as a Framework for Inclusive Dialogue, Learning and Accountability for Social Impact.

Mayasari, Riana. 2016. "Evaluasi Penyusunan Laporan Akuntabilitas Kinerja Studi Pada Dinas Pekerjaan Umum Pengairan Provinsi Sumatera Selatan." Universitas Gadjah Mada.

Mayasari, Riana and Jovan Febriantoko. 2018. "See More: Evaluation of Work Programs and Financial Performance of Local Government in Indonesia Through Cipp Model." International Journal of Contemporary Research and Review 9(12):21169-78.
Mayasari, Riana and Herlan Junaidi. 2018. Laporan Pengabdian Kepada Masyarakat: Penataan Penyusunan Informasi Kinerja RKA Dinas Pengelolaan Sumber Daya Air Provinsi Sumatera Selatan Berbasis Logic Model(Pengantar). Palembang.

Sherman, Paul David. 2016. "Using RUFDATA to Guide a Logic Model for a Quality Assurance Process in an Undergraduate University Program." Evaluation and Program Planning 55:11219. 